EPiC Series in Engineering
Volume 3, 2018, Pages 199-206
HIC 2018. 13th International
Conference on Hydroinformatics

\title{
High-resolution LiDAR bathymetry data for alpine rivers Case study on the Mareit/Mareta River, Italy
}

\author{
Katharina Baumgartner ${ }^{1}$, Robert Klar $^{1}$, Markus Aufleger ${ }^{1}$ \\ ${ }^{1}$ University of Innsbruck, Unit of Hydraulic Engineering, Technikerstr. 13, 6020 Innsbruck, \\ Austria \\ katharina.baumgartner@uibk.ac.at
}

\begin{abstract}
The many facets of river hydromorphology are of crucial importance to assess the condition of rivers. Generating new knowledge is the key in achieving the water framework objectives. Therefore, detailed bathymetric information is required for each river system to evaluate the constantly changing morphological structures and to understand hydraulic, morphodynamic and ecological processes. The technology of Airborne LiDAR Bathymetry (ALB) scanning is an innovative remote sensing method for measuring the 'underwater topography' of water bodies. ALB is perfectly qualified to meet the requirements at an exceptionally high resolution and sufficient accuracy. The data processing of an ALB point cloud consists of a number of specific work steps to determine the point classification (water surface, bathymetry, vegetation, ground, etc.) and to derive high-quality digital terrain models (DTM). This work shows exemplary the results of an ALB survey of the Mareit/Mareta River in South Tyrol, Italy. First, the applied analysis methodology is presented. Second, the question on the optimal bathymetric resolution for hydraulic and habitat modeling purposes is discussed.
\end{abstract}

\section{Introduction}

For achieving the objectives of the EU Water Framework Directive (WFD), a diversified river hydromophology is of paramount importance, in addition to chemical, physico-chemical and biological components (European Union). For evaluation of morphological processes and for characterizing morphological structures in river systems, full bathymetric information of different bathymetric points over time is necessary. With high-resolution digital terrain data sets, the evaluation of hydro-morphological pressures with mesohabitat models, even for long river stretches in remote alpine areas, becomes possible (Dobler et al., 2014). The time-consuming classical terrestrial cross- 
High-Resolution LiDAR Bathymetry Data for Alpine Rivers - Case Study on ...K. Baumgartner et al.

section survey in river engineering is increasingly being supplemented or replaced by new remote sensing technologies and data processing methods. The technology of airborne LiDAR bathymetry (ALB) scanning allows reliable and fast data acquisition of complex morphological structures with a previously unattained high resolution (Kinzel et al., 2013), and can be applied successfully, even in inaccessible alpine regions (Mandelburger et al., 2011, Aufleger et al., 2015). A water-penetrating laser system uses the green region of the electromagnetic spectrum (wavelength $=532 \mathrm{~nm}$ ) to detect and to measure shallow coastal waters, lakes and rivers (Steinbacher et al., 2012, Mandelburger et al., 2011). The result obtained the water surface and the 'underwater topography' with a point density up to 50 points $/ \mathrm{m}^{2}$.

This work addresses the analysis of high-resolution ALB data for the $3 \mathrm{~km}$ Mareit/Mareta River in South Tyrol, Italy. With repeated surveys, it is possible to identify morphological changes such as relocation of hydro-morphological units. The focus in this work is on post-processing steps of the ALB data set, validation of data quality, and bathymetric resolution. It is part of the research project FHARMOR - Fish Habitat in Alpine Rivers: Integrating Monitoring, Modelling and Remote Sensing (http://www.fharmor.it/), which is dedicated to improving state-of-the-art habitat simulation and evaluation methodologies.

\section{Methodology}

\subsection{Study Area}

The study area is located in the province of South Tyrol in Italy (Figure 1). Here, the alpine Mareit River originates at an elevation of about $3471 \mathrm{~m}$ a.s.l. and flows into the Eisack River at $935 \mathrm{~m}$ a.s.1. on the southern edge of the city of Sterzing. With a total length of $25 \mathrm{~km}$ and a catchment area of 212 $\mathrm{km}^{2}$, including glacier area of about $9 \mathrm{~km}^{2}$, the river is characterized by a nivo-glacial flow regime with diurnal cycles in summer. The mean annual discharge at the "Mareiterbach" gauging station downstream of the study area is approximately $7 \mathrm{~m}^{3} / \mathrm{s}$.

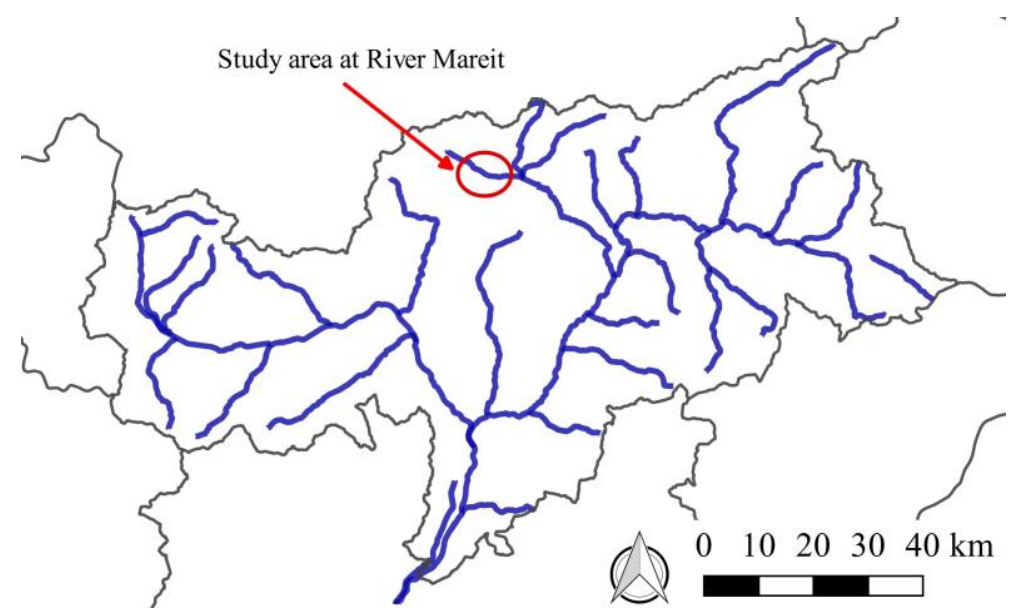

Figure 1: Overview map of South Tyrol, Italy with marked study area - drainage area of Mareit River.

The first ALB survey was carried out on December 15th, 2016 for a $3 \mathrm{~km}$-long semi-confined reach, located downstream of the village, Mareit. This river stretch was heavily modified during the last century by channelization and the construction of several grade-control structures. In 2009 it was restored on behalf of the department of Hydraulic Engineering, Autonomous Province of Bolzano. 
High-Resolution LiDAR Bathymetry Data for Alpine Rivers - Case Study on ...K. Baumgartner et al.

The homogeneous and channelized river turned back into a wide and self-forming river system, which has already developed braided patterns with an average channel gradient about $1.3 \%$ (Figure 2). Bedload transport from the catchment area controls the channel formation. Brown trout (Salmo trutta fario) and marble trout (Salmo marmoratus) dominate the fish community. Through the river restoration, the longitudinal fish migration is again possible and an increase the biological quality of the river has been caused.
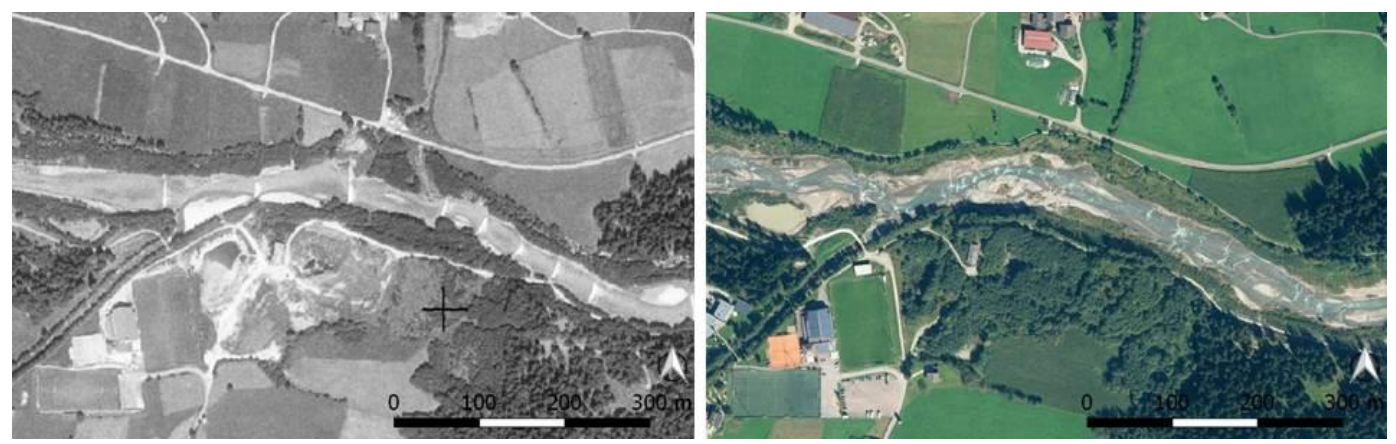

Figure 2: Orthophoto of the study reach "Mareit River" before (left) and after restoration (right)

\subsection{Survey data and Data Sets}

In order to analyze morphological structures, a high-resolution bathymetric data set was collected by the company AirborneHydroMapping GmbH (ahm.co.at) using state-of-the-art ALB scanning technology. The latest sensor development of the Austrian company RIEGL Laser Measurement Systems GmbH - the topo-bathymetric sensor VQ-880-G (Riegl - Datasheet) - was part of the onboard system equipment. The aircraft flight acquisition was conducted at an altitude $600 \mathrm{~m}$ above the ground. With a pulse repetition rate of $550 \mathrm{kHz}$, a high scanning speed and the narrow laser beam reach, a high spatial resolution up to $20-50$ points $/ \mathrm{m}^{2}$ was achieved. The typical measurement range into the water can be up to 1.5 secchi depth for bright conditions (Riegl - Datasheet). These characteristics facilitate the acquisition of morphological patterns in inaccessible alpine catchment areas (Dobler et al., 2014). Application may be limited for example by intense turbidity and white water. The resulting point data of the study area included 12 single strips to achieve a consistent data set. The survey flight took place on December $15^{\text {th }}, 2016$ under leafless and low flow conditions. At the same time, aerial photographs were taken, which is a clear advantage for the data post-processing. Simultaneously, FHARMOR team members carried out comprehensive field measurements on the ground including terrestrial surveys and manual discharge measurements for data validation and - in a broader sense - to calibrate the numerical models.

The pre-processing of the scan data was done by using the RIEGL software RiPROCESS (Riegl RiProcess Datasheet) and included the two work steps raw data processing and strip adjustment. The accuracy of the adjustment is about $\pm 7 \mathrm{~cm}$ (standard deviation, short: std). Subsequently, the point cloud was georeferenced to UTM 32N (ETRS89) coordinates using terrestrial reference planes. These planes refer to roof surfaces and crosswalks, which can be easily identified within the point cloud and are distributed across the study area. The main last step in the pre-processing was the correction of the water-depth points (refraction) using the specialized software HydroVISH (based on VISH - the Vish Visualization Shell). 
High-Resolution LiDAR Bathymetry Data for Alpine Rivers - Case Study on ...K. Baumgartner et al.

\subsection{Data quality and point cloud classification}

The high resolution of the ALB data allows the detection of the main topographic (above the water surface) and bathymetric (below the water surface) structures. Data control is essential to ensure data quality (McKean et al., 2014). Thanks to the simultaneously captured aerial images during the ALB survey, a visual comparison of the point cloud and the corresponding images was possible. The software HydroVISH offers several dedicated functions and procedures for automatic and manual classification. Additionally, the user benefits from the advantages of the data format HDF5 (HDFGroup). First, the full ALB point cloud of the study area was classified based on automatic procedures e.g. planar regression and deletion of negative outliers below a defined base level. The application generated good results for areas with uniform bed morphology. In a second step, the automatically generated classification had to be revised for non-uniform bed areas with big rocks. Figure 3 shows the final classified point cloud.

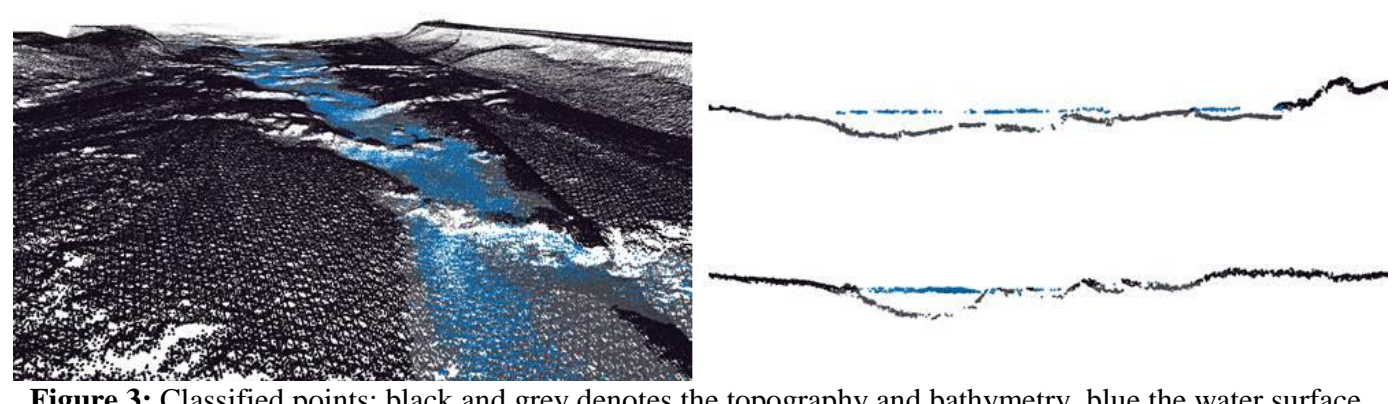

Figure 3: Classified points: black and grey denotes the topography and bathymetry, blue the water surface.

\subsection{Point cloud accuracy and bathymetric resolution}

The accuracy validation of the captured point cloud is of utmost importance. The terrestrial measured points recorded during the flight day are compared with the original classified LiDAR point cloud. The results are described by the mean deviation (median), RMSE (root-mean-square-error) and standard deviation (std). The RMSE is calculated as

$$
R M S E=\sqrt{\sum\left(z_{A L B}-z_{t e r r}\right)^{2} / n}
$$

where $\mathrm{z}_{\mathrm{ALB}}$ is the elevation of the classified LiDAR point cloud, $\mathrm{z}_{\mathrm{terr}}$ is the terrestrial elevation at the same location and $\mathrm{n}$ is the number of evaluated points.

A high level of detail has many advantages for bathymetric terrain analysis. Nevertheless, for applications with high computational expense it is necessary to produce a manageable amount of data. Therefore, based on the original classified data point cloud, uniform raster data sets with resolutions of $0.25,0.50$ and $1.00 \mathrm{~m}$ were generated. Finally, the structural diversity of the original bathymetric resolution was compared to the resulting raster sets to ensure that no significant information is missing and the quality of the grid is suitable. 
High-Resolution LiDAR Bathymetry Data for Alpine Rivers - Case Study on ...K. Baumgartner et al.

\section{Results and Discussion}

Figure 4 (a) shows the high level of detail of the full ALB point data set after strip adjustment. Low water temperatures (about $0.5{ }^{\circ} \mathrm{C}$ ) at the study area around the survey date in December caused an ice cover over a large part of the floodplain (Figure 4 (b)). These areas are clearly visible in the LiDAR data set and the aerial images. Unfortunately, for the purpose of detecting morphodynamic changes between two ALB surveys, ice covered areas are of no use and had to be removed. The final selected study area captures a $1.5 \mathrm{~km}$ long reach and has an area around $138.000 \mathrm{~m}^{2}$.
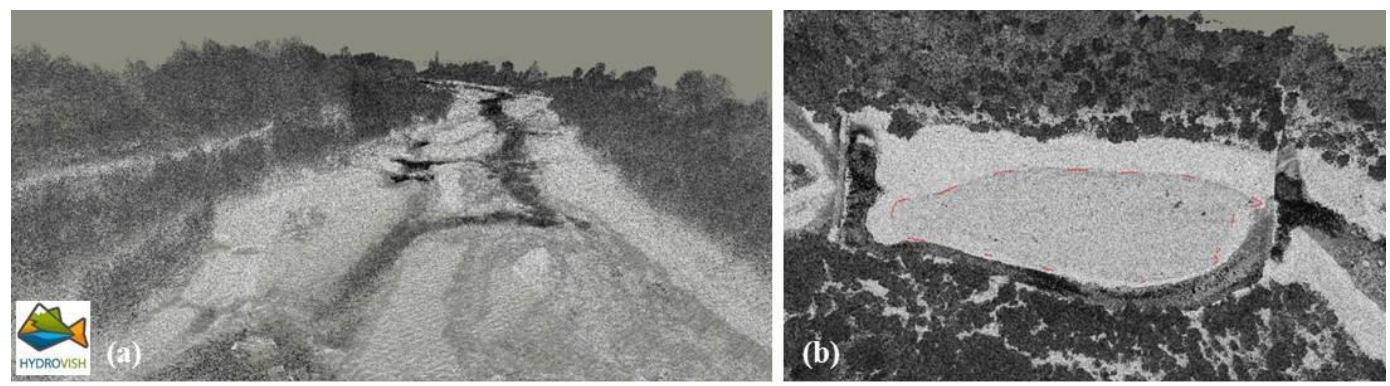

Figure 4: (a) Raw data point cloud including the vegetation, (b) point cloud with ice cover.

The HydroVISH built-in algorithms for automatic point cloud classification generate relatively good classification qualities for rivers with few morphological structures. However, the classification quality for the Mareit River stretch was too inaccurate to represent the full variety of the morphological features present. Therefore, important patterns like boulders, big rocks or older ramps consisting of boulders had to be re-classified manually in a subsequent step in line with the morphological focus of the project. With the overlapping flight strips, the final classified point density is around 140 points $/ \mathrm{m}^{2}$. Figure 5 displays the generated digital terrain model (DTM) based on the classified point cloud.

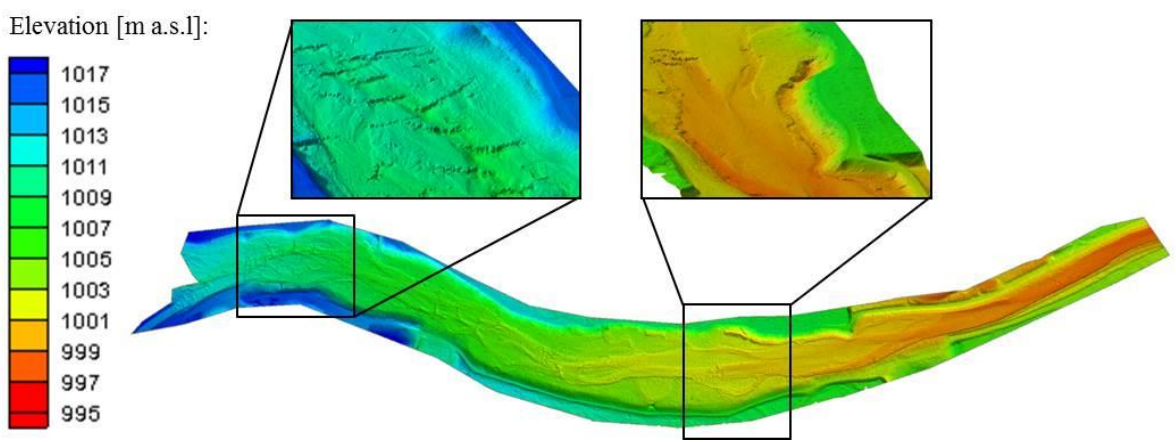

Figure 5: Generated mesh based on the classified data set with focus on morphological structures.

To evaluate the accuracy of the ALB point cloud, the differences between the elevation of the terrestrial measured points and the ALB elevation at the corresponding position were used to assess the vertical precision. The statistical parameters (median, RMSE and standard deviation) were calculated and are shown in Figure 6. The RMSE for terrain point precision is determined as 0.032 and for the water surface about 0.036 . The relative frequency nearly shows a normal distribution. About $80 \%$ of all evaluated points are within the $\pm 4 \mathrm{~cm}$ discrepancy and thus are below the GPS accuracy. The result of the water surface accuracy shows a slight deviation. It should be mentioned here, that terrestrial measured water surface points exhibit higher uncertainties. Tangentially, the true 
High-Resolution LiDAR Bathymetry Data for Alpine Rivers - Case Study on ...K. Baumgartner et al.

water surface is below the terrestrial measured one. This deviation is not very remarkable and is acceptable for the calibration of hydraulic models.
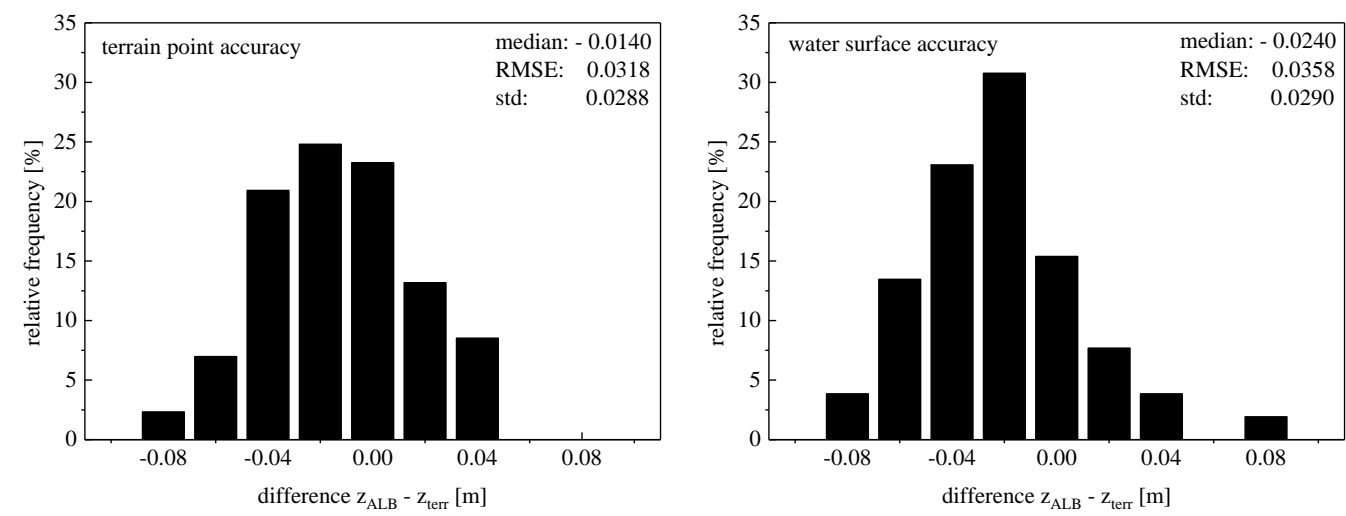

Figure 6: ALB accuracy results against terrestrial measured points; left picture shows the deviation from the terrain points and right the deviation of the water surface points.

One task was to generate a point cloud with a manageable size for further applications, without losing the main morphological structures in the riverbed. In order to cope with this, uniform grids with grid widths of $0.25 \mathrm{~m}$ (designation: raster025), $0.50 \mathrm{~m}$ (raster050) and $1.00 \mathrm{~m}$ (raster100) were generated. The newly created point clouds are always characterised by much lower point densities. The geometric differences between the classified point cloud (PW) with full resolution and the grid raster025 and raster050 are in an acceptable range, especially if the advantage of the more easily handled data is considered. Table 1 gives an overview of some data properties for the different raster grid data sets. The associated visual bathymetric resolution is shown in Figure 7. The average point density for the grid raster025 is $15 \mathrm{Pt} / \mathrm{m}^{2}$ and becomes very wide-meshed with $1 \mathrm{Pt} / \mathrm{m}^{2}$ for the grid raster100.

\begin{tabular}{lrr}
\hline Data Set & Number of nodes & Point Density \\
\hline Classified point cloud $(\mathrm{PW})$ & $\sim 19.428 .000$ & $\sim 140 \mathrm{Pt} / \mathrm{m}^{2}$ \\
Raster025 $(0.25 \times 0.25 \mathrm{~m})$ & $\sim 2.140 .000$ & $\sim 15 \mathrm{Pt} / \mathrm{m}^{2}$ \\
Raster050 $(0.50 \times 0.50 \mathrm{~m})$ & $\sim 547.000$ & $\sim 4 \mathrm{Pt} / \mathrm{m}^{2}$ \\
Raster100 $(1.00 \times 1.00 \mathrm{~m})$ & $\sim 138.000$ & $\sim 1 \mathrm{Pt} / \mathrm{m}^{2}$
\end{tabular}
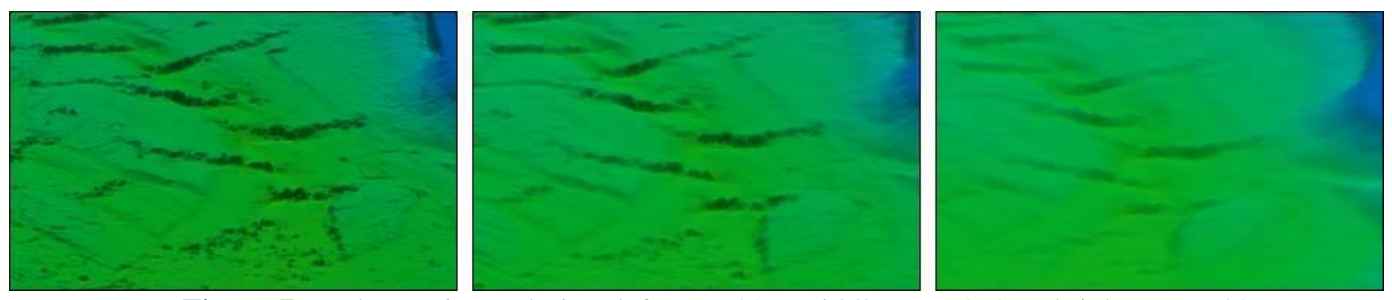

Figure 7: Bathymetric resolution, left raster025, middle raster050 and right raster100.

The validation of the different raster data sets was performed by comparing the 3D coordinates of the terrestrial measured points with the corresponding points in the three raster data sets raster025, raster050 and raster100. Figure 8 illustrates the spatial distribution of all compared reference points at cross sections. The figure additionally shows boxplots of all created raster data sets with the corresponding outliers. The median deviation is -0.016 for raster025 and $-0.024 \mathrm{~m}$ for raster 100 . It is 
High-Resolution LiDAR Bathymetry Data for Alpine Rivers - Case Study on ...K. Baumgartner et al.

remarkable that the outliers in raster100 increase compared to raster025 and raster050. Large deviations occur close to stone structures and rapid bathymetry changes. Raster100 contains the steppool frequencies, but the exact location of the drops get lost.
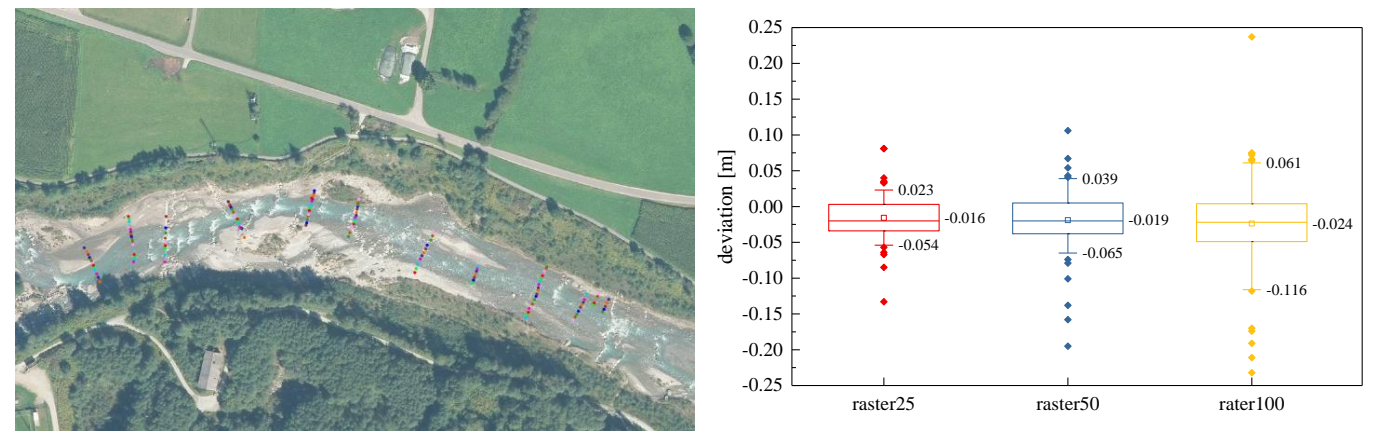

Figure 8: Reference points for validation of raster data sets (raster025, raster050, raster100).

Figure 9 illustrates the elevation differences between raster025 and raster100 for a selected section. In areas with few spatial changes, the presented pictures show negligibly small differences between high and low resolution point clouds. Nevertheless, the low-resolution grids loose information at locations with steep, rapidly changing bathymetry, like hydraulic drops. These areas are displayed in colour. A smearing in the degree of detail is visible. This lack in detail may affect the computation results of hydraulic models. The challenge is to find the most wide-meshed resolution to receive fast computation times, which contains all specific geometric features at the same time e.g. points from ramp edges or boulders. For more accurate investigations, this knowledge must be examined on hydraulic models.
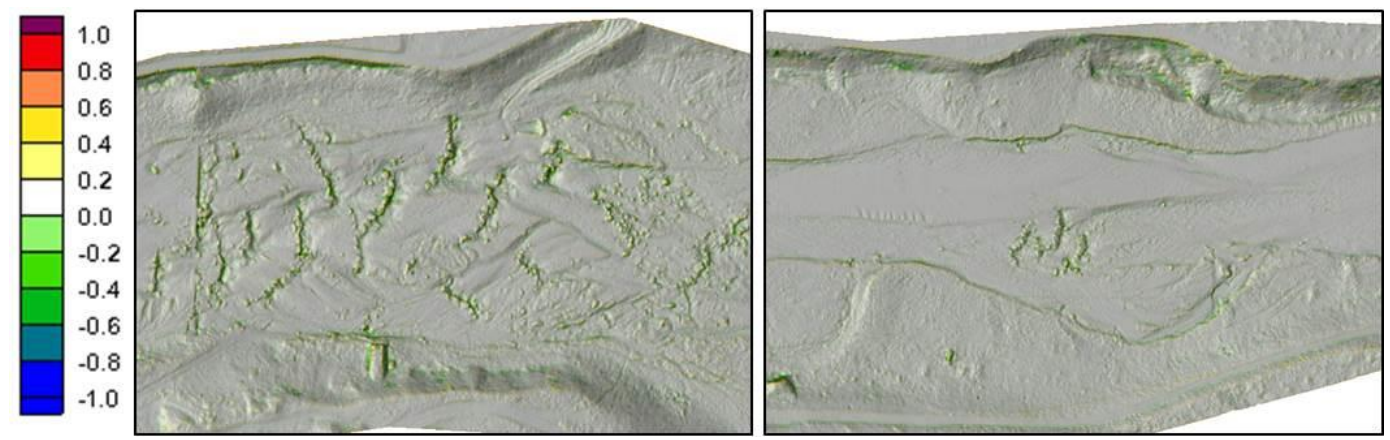

Figure 9: Elevation differences between raster data set raster025and raster100.

\section{Conclusion}

The study shows a typical result from an airborne LiDAR bathymetric survey. The advantage of ALB compared to classical terrestrial river survey is primarily the much higher resolution of bathymetric information. In order to describe complex morphological structures and high-dynamic processes in river systems an accurate, fast and reliable measurement of the bathymetry is crucial. A revision of the classification process to improve its applicability has resulted in satisfactory results. The precision of the terrain ground points has shown good levels of accuracy. The elevation of the water surface shows in general a lower accuracy, due to the higher uncertainties of the moving water surface. The reduction of the point density produced differences between the data sets, especially in 
High-Resolution LiDAR Bathymetry Data for Alpine Rivers - Case Study on ...K. Baumgartner et al.

steep, rapidly changing bathymetry. The survey and post-processing methodology is suitable to generate customized raster grids for different research questions.

\section{Application and Outlook}

River morphological changes affect the river ecology and result in habitat changes at mesoscale. In the last decades, habitat models have grown in significance but there still was a lack of information about the morphodynamic processes. The technology of Airborne LiDAR Bathymetry (ALB) scanning is used in the FHARMOR project to extend the applicability of mesohabitat models to nonwadeable conditions for long river stretches and is applied also for alpine rivers. A repetitive topobathymetric LiDAR survey is a crucial component to capture the hydro-morphological units and monitor instream habitats. Therefore, the ALB technology will make a huge contribution in achieving the goals of the European Water Directive.

\section{References}

Aufleger, M., Steinbacher, F., Baran, R., Valerie, N. (2015). Airborne Hydomapping Hochaufgelöste Gewässervermessung "wie im Flug", 38. Dresdner Wasserbaukolloquium 2015, Dresden

Dobler, W., Steinbacher, F., Baran, R., Ritter, M., Aufleger, M. (2014). High Resolution Bathymetric Lidar Data to Hydraulic - Modelling a Mountain Stream by Bathymetric Lidar Data. In: Proceedings of the 11th International Conference on Hydroinformatics (HIC 2014). New York City

European Union. (n.d.). Directive 2000/60/EC of the European Parliament and of the Council of 23 October 2000 Establishing A Framework for Community Action the Field of Water Policy. Retrieved from http://eur-lex.europa.eu/legal-content/DE/TXT/?uri=celex:32007L0060

HDF-Group (n.d.). The HDF5 Home Page. Retrieved from www.hdfgroup.org

Kinzel, P.J., Legleiter, C.J., Nelson, J.M. (2013). Mapping River Bathymetry with a Small Footprint Green LiDAR: Applications and Challenges. JAWRA Journal of the American Water Resources Association 49, pp. 183 - 204

Mandelburger, G., Pfenningbauer, M., Steinbacher, F., Pfeifer, N. (2011). Airborne Hydrografic LiDAR Mapping - Potential of a new technique for capturing shallow water bodies. 19th International Congress on Modelling and Simulation, Perth, Australia

McKean, J., Tonina, D., Boh, C., Wright, C.W. (2014). Effects of bathymetric lidar errors on flow properties predicted with a multi-dimensional hydraulic mode, Journal of geophysical research: Earth Surface 119, Volume 119, issue 3, pp. 664-664

Riegl. RiProcess Datasheet, 2017. (n.d.). Retrieved from http://www.riegl.com/uploads/ tx_pxpriegldownloads/11_Datasheet_RiProcess_2016-09-16.pdf

Riegl, VQ-880-G Datasheet 2017. (n.d.). Retrieved from http://www.riegl.com/uploads/tx_ pxpriegldownloads/Infosheet_VQ-880-G_2016-05-23.pdf

Steinbacher, F., Pfenningbauer, M., Aufleger, M., Ullrich, A. (2012). High Resolution Airborne Shallow Water Mapping. International Archieves of the Photogrammetry, Remote Sensing and Spatial Information Sciences, Volume XXXIX-B1, 2012 XXII ISPRS Congress, Melbourne, Australia 